\title{
Design and Implementation of Torque Control and Estimation for an Electric Hand-Tool
}

\section{Tian-Hua Liu*, Cheng-Wei Peng}

Department of Electrical Engineering, National Taiwan University of Science and Technology, Taiwan. E-mail: liu@mail.ntust.edu.tw

\begin{abstract}
This paper proposes the design and implementation of torque control and torque estimation for an electric hand-tool. This hand-tool does not require any torque transducer or any Hall-effect sensor. Only some low-cost resistances are used to measure the stator currents of a brushless DC motor, which is used to drive the hand-tool. Novel 3-phase current commands are proposed here to obtain greater torque than traditional 3-phase, square-wave current commands. The output torque of the hand-tool can be estimated and displayed by an LED display. A PI controller is used to achieve the current-loop control. A digital signal processor, TMS-320-F2808 that was manufactured by Texas Instruments, is used to execute the control and estimation algorithms. Experimental results show the correctness and feasibility of the proposed methods.
\end{abstract}

Keywords: Brushless DC Motor; Electric Hand-Tool; Torque Estimation; Digital Signal Processor

\section{Introduction}

Traditional hand-tools are powered by human's hands; however, the torque that is produced by human hands is limited and cannot be kept at a constant. To solve this problem, electric hand-tools have become more and more popular, as they provide the required amounts of constant output torque.

Electric hand-tools can be driven by DC motor drive systems or brushless DC motor drive systems, which do not require commutators and brushes, and can provide high efficiency, low inertia, small volume, and low noise. Brushless DC motor drives are gradually replacing DC motor drives and have become a new trend. Several papers have investigated these types of electric hand-tools. For example, Huang et al. proposed the implementation of hybrid power supply systems with energy regulation capability for hand-held tools ${ }^{[1]}$. Hesmondhalgh et al. studied low-speed motorized dental hand-tools, in which the motor gearing, case temperature and control were considered ${ }^{[2]}$. In addition, Hesmondhalgh et al. designed a high-speed, high-performance, direct-drive hand-tool, which could reach $10 \mathrm{~W}$ and $150000 \mathrm{r} / \mathrm{min}^{[3]}$. Mecrow implemented high torque electric machines for power hand-tool applications, and two different electric machines were built ${ }^{[4]}$. Koinuma et al. also designed a novel self-cooling switched reluctance motor for electric hand-tools ${ }^{[5]}$, and Sathyan et al. proposed an FPGA-based novel digital PWM control scheme for brushless DC motor drives ${ }^{[6]}$.

To display the output torque, a torque sensor, is generally used in electric hand-tools. However, torque sensors are very expensive. To solve the problem, in this 
paper, a torque sensor estimator of the electric hand-tool is proposed by measuring the stator currents of a brushless DC motor, and the accuracy of the estimated torque is satis-factory. In addition, a $\Delta$ - connected, 3-phase, brushless DC motor drive system is implemented and driven by 6 MOSFETs. The implemented brushless DC drive system can provide greater torque than the torque provided by traditional Y-connected $120^{\circ}$ conduction, square-wave command, brushless DC motor drive system.

To the authors' best knowledge, the ideas proposed in this paper are original and have not been published in previous research $^{[1-6]}$. The organization of the paper is as follows. First, the system description is presented. Next, the torque control method is proposed. After that, the implementation is discussed. Finally, some experimental results and conclusions are included.

\section{System description}

\subsection{Electric hand-tool system}

Electric hand-tools are widely used in industrial applications and home appliances. They provide the functions of driving screws and cutting and drilling wood or metal. As a result, the speed control and torque control play the main roles in the electric hand-tools. The configuration of the regular electric hand-tool is shown in Figure 1(a), including a brushless DC motor, an inverter and its control circuit, a gear, a torque sensor, a Li-battery set, and a push button. The brushless DC motor provides better performance than a brush DC motor in many aspects. Compared to a brush DC motor, the brushless DC motor does not require any mechanical brush or commutator. As a result, the brushless DC motor produces less noise and arc, and it has a longer life than the brush DC motor. In addition, the brushless DC motor does not have any mechanical contacts and has a lower inertia than a brush DC motor. In this paper, the brushless DC motor is a $\Delta$ - connected 3-phase, 4-pole, rated $26000 \mathrm{r} / \mathrm{min}, 1 \mathrm{~kW}$ motor which was manufactured by John Electric Company. An inverter, which is a 3-leg, 6-MOSFETs, pulse-width-modulated current-regulated voltage-source inverter, is implemented to drive the brushless DC motor. The switching frequency of the inverter, in general, is near $10 \mathrm{kHz}$. The gear used here is a plenary gear, which is shown in Figure 1(b). It has several advantages, including light weight, small volume, high efficiency, high gear ratio, and low noise. The plenary gear set consists of three major parts: a sun gear, a plenary gear, and a ring gear. When torque is applied to the sun gear, the sun gear rotates and then the plenary gear rotates to different angles around the sun gear. The gear ratio can be expressed as follows.

$$
N_{g}=\frac{N_{r}}{N_{s}}+1
$$

where $N_{g}$ is the gear ratio of the gear set, $N_{r}$ is the number of teeth on the ring gear, $N_{s}$ is the number of teeth on the sun gear. The Li-battery set, made by Metabo Company, provides $18 \mathrm{~V}$ and $4 \mathrm{Ah}$ power. The Li-battery has a very high power density, and it can provide more electrical energy than other batteries. The push button is used to control the electric hand-tool. 


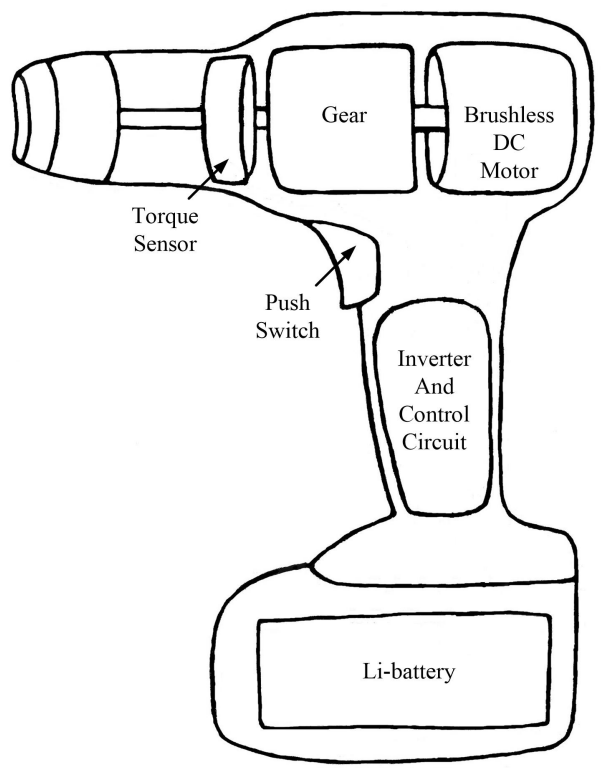

(a)

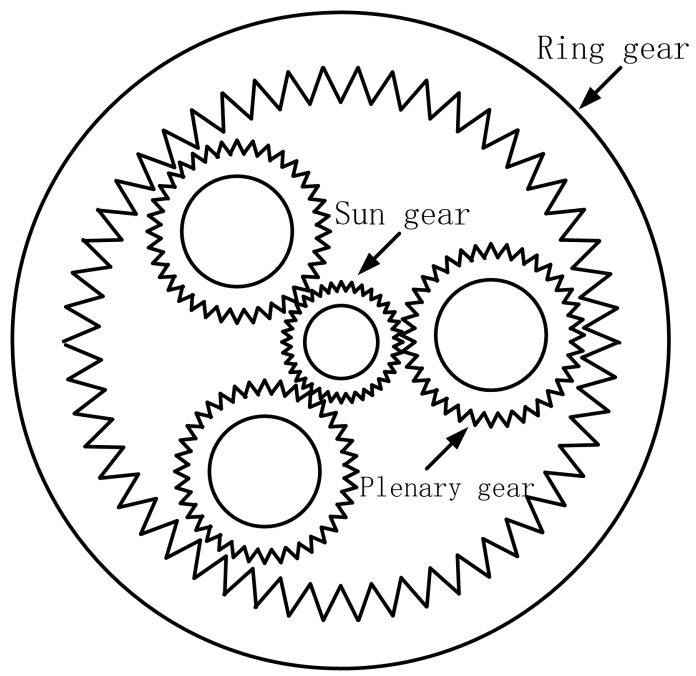

(b)

Figure 1. The configuration of the electric hand tool. (a) structure (b) gear.

\subsection{Brushless DC motor}

In the stationary frame, a three-phase, Y-connected brushless DC motor has the phase-voltage equations as follows

$$
\left[\begin{array}{c}
v_{U} \\
v_{V} \\
v_{W}
\end{array}\right]=\left[\begin{array}{ccc}
r_{S} & 0 & 0 \\
0 & r_{S} & 0 \\
0 & 0 & r_{S}
\end{array}\right]\left[\begin{array}{c}
i_{U} \\
i_{V} \\
i_{W}
\end{array}\right]+\left[\begin{array}{ccc}
L & L_{M} & L_{M} \\
L_{M} & L & L_{M} \\
L_{M} & L_{M} & L
\end{array}\right] \frac{d}{d t}\left[\begin{array}{c}
i_{U} \\
i_{V} \\
i_{W}
\end{array}\right]+\left[\begin{array}{c}
e_{U} \\
e_{V} \\
e_{W}
\end{array}\right]
$$

where $v_{\mathrm{U}}, v_{V}, v_{W}$ are the $u$-, v-,w-phase voltages, $r_{S}$ is the stator resistance, $L$ is the self-inductance, $L_{M}$ is the mutual-inductance, $\frac{d}{d t}$ is the differential operator, $i_{U}, i_{V}, i_{w}$ are the $u-, v-$, $w$-phase currents, and $e_{U}, e_{V}, e_{W}$ are the $u$-, $v$-, $w$-phase back EMFs.

The back-EMFs can be expressed as

$$
\left[\begin{array}{l}
e_{U} \\
e_{V} \\
e_{W}
\end{array}\right]=\omega_{e} \lambda^{\prime}\left[\begin{array}{c}
f\left(\theta_{e}\right) \\
f\left(\theta_{e}-\frac{2 \pi}{3}\right) \\
f\left(\theta_{e}+\frac{2 \pi}{3}\right)
\end{array}\right]
$$

where $\omega_{e}$ is the electrical rotor speed, $\lambda^{\prime}$ is the equivalent flux-linkage, $f\left(\theta_{e}\right)$ is the trapezoidal function, and $\theta_{e}$ is the electrical rotor position. 
The electromagnetic torque is

$T_{e}=\frac{P}{2} \lambda^{\prime}\left[i_{U} f\left(\theta_{e}\right)+i_{V} f\left(\theta_{e}-\frac{2 \pi}{3}\right)+i_{W} f\left(\theta_{e}+\frac{2 \pi}{3}\right)\right]$

where $T_{e}$ is the electromagnetic torque, and $P$ is the pole number. The torque equation can also be expressed as follows

$T_{e}=K_{t}\left[i_{U} f\left(\theta_{e}\right)+i_{V} f\left(\theta_{e}-\frac{2 \pi}{3}\right)+i_{W} f\left(\theta_{e}+\frac{2 \pi}{3}\right)\right]$

where $K_{t}$ is the torque constant. The dynamic speed equation is

$$
\frac{d}{d t} \omega_{m}=\frac{1}{J_{m}}\left(T_{e}-T_{L}-B_{m} \omega_{m}\right)
$$

where $J_{m}$ is the inertia of the motor and load, $\omega_{m}$ is the mechanical rotor speed, $B_{m}$ is the viscous coefficient of the motor and load, and $T_{L}$ is the external load.

Figure 2(a) shows the structure of the brushless DC motor. The brushless DC motor consists of three major parts: a stator with three-phase concentrated windings, an air gap, and a rotor with mounted permanent magnetic material on its surface. Figure 2(b) shows the relationship between the back EMF and its related stator phase current which is proposed in this paper. The detailed principle is discussed in section 3 .

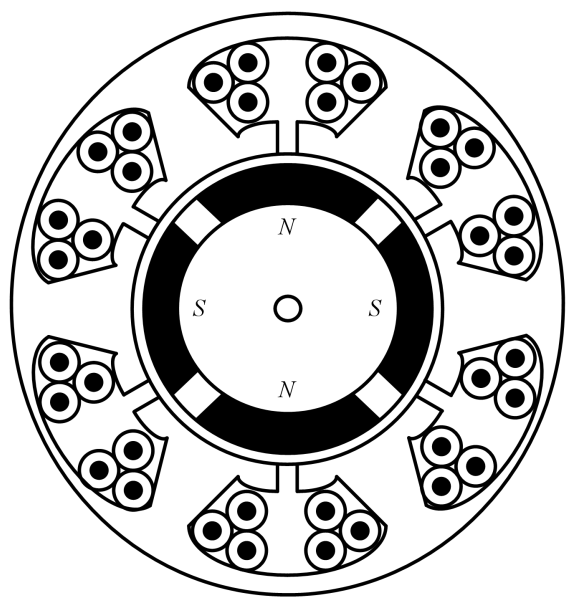

(a)

\section{Back-EMF and Current}

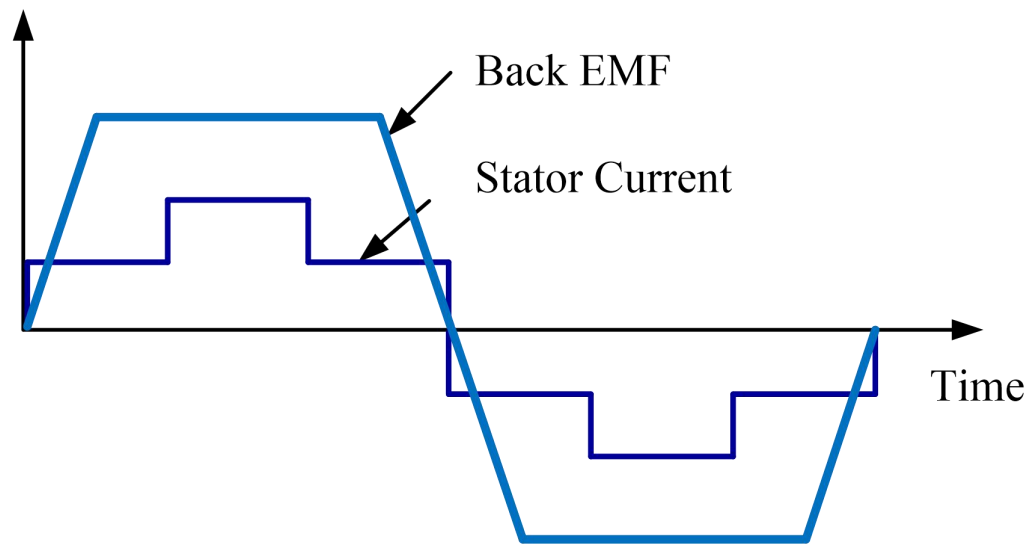

(b)

Figure 2. The brushless DC motor. (a) stator (b) waveforms.

\section{Torque control method}

Several different current waveforms have been investigated in previous studies to obtain better torque performance of brushless DC drive systems. For example, there are two types of current command modest - the $120^{\circ}$ conduction mode and the $180^{\circ}$ conduction mode $\mathrm{e}^{[7,8]}$. In addition, a split-supply-converter topology, which uses a single switch per phase was previously proposed ${ }^{[9]}$. 
This method can obtain good current regulation; however, the method is very complicated. To obtain a high power density and a large output torque, in this paper, a novel $180^{\circ}$ conduction mode is first proposed by the authors. The basic waveforms are shown in Figure 3. The brushless DC motor has a trapezoidal waveform of back EMFs with a constant magnitude. This trapezoidal back EMF has both positive and negative back EMFs, as shown in $e_{U}, e_{V}$, and $e_{w}$ in Figure 3. In addition, the $e_{U}, e_{V}$, and $e_{w}$ have a $120^{\circ}$ phase shift among them. In this paper, to obtain a high output torque and a high power density, novel phase-current commands of the brushless DC motor shown as $i_{U}, i_{V}$, and $i_{w}$ in Figure 3 are proposed. The phase current includes two-steps in the positive current and two-steps in the negative current. In addition, the phase-shifts among the $a-, b$-, and $c$-phase are $120^{\circ}$. Next, the DSP computes the $u$-phase power, which is equal to $e_{U} i_{U}$; the $v$-phase power, which is equal to $e_{V} i_{V}$; and the $w$-phase power, which is equal to $e_{w} i_{w}$.
Finally, the total power $P_{o}$, which has the same waveform as the output torque $T_{e}$, is shown in Figure 3. The output torque has 6 torque pulsations in $360^{\circ}$. In fact, the torque increases in the first $30^{\circ}$, and then decreases in the next $30^{\circ}$. The average torque, however, is very smooth. The proposed method has several advantages. First, the phase-current is easily generated and the change of the current in the 2-level waveform is quite small. Furthermore, the current pulsations change 12 times in one electric cycle. As a result, the motor produces smooth speed due to the large inertia of the motor and load. Although the proposed method does not obtain a constant torque, the motor has a $180^{\circ}$ conduction mode, and this mode has a longer conduction angle than the $120^{\circ}$ conduction mode. As a result, the output torque and output power of the proposed method are greater than the $120^{\circ}$ conduction mode. This is one major contribution of this paper. For applications to electric hand-tools, generally speaking, greater torque is more important than smooth torque. 


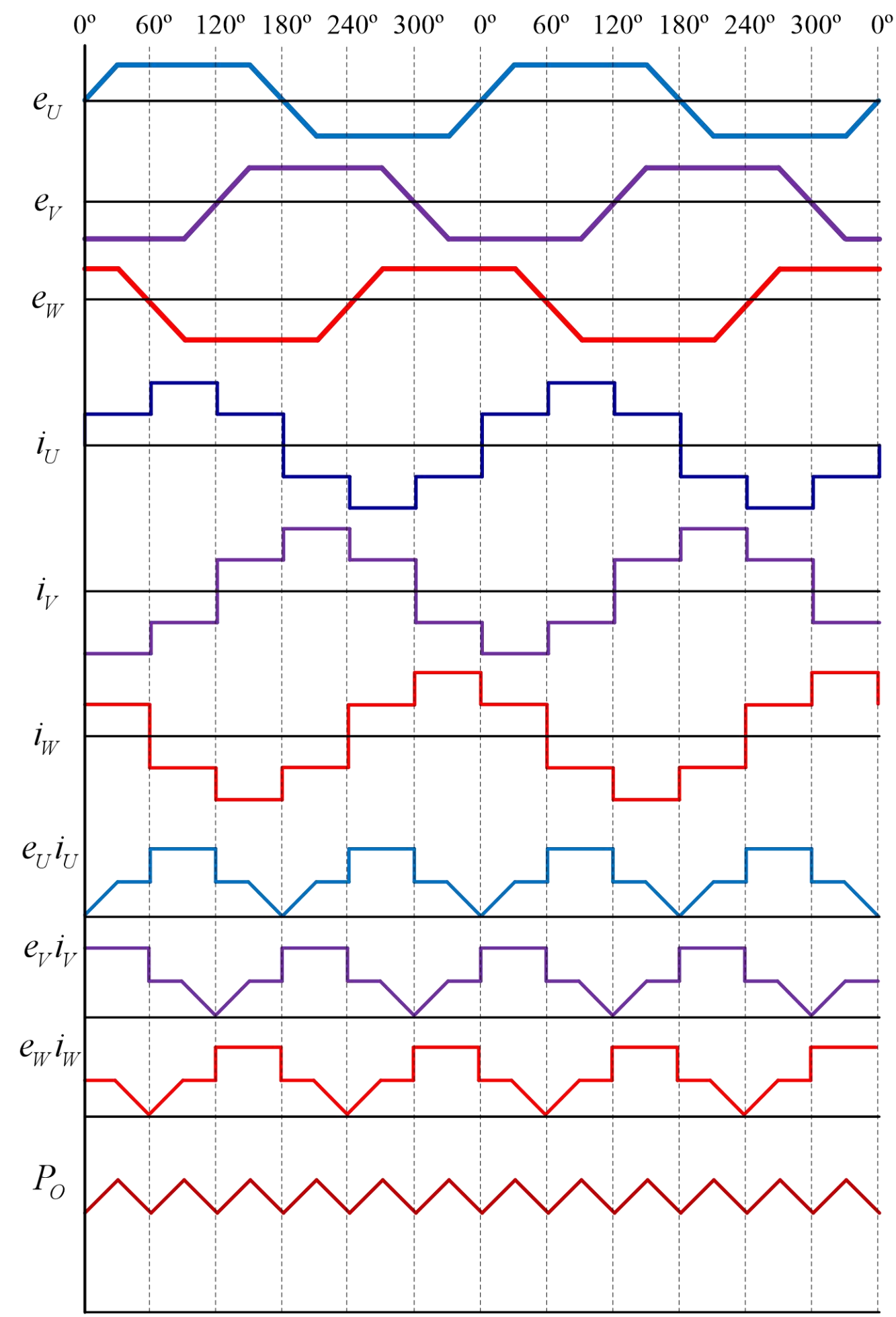

Figure 3. The waveforms of the brushless DC motor.

\begin{abstract}
A $\Delta-\quad$ connected three-phase
\end{abstract}
MOSFET-driven brushless DC motor drive system is implemented and shown in Figure 4(a) in this paper. The efficiency of the brushless DC motor, which is the ratio of the mechanical output power to the electrical input power, is higher than the Y-connected three-phase
MOSFET-driven brushless DC motor. The reason is that the power in the $\Delta$ - connected three-phase brushless DC motor is greater than the power in the Y-connected motor. The drive system is often called a "bipolar drive", in which the winding in the motor is alternatively energized in the south and north poles. 
Figure 4(b) shows the comparison of the related waveforms between the phase-current commands and the line-current commands. The phase-current commands have two levels in the positive current and two levels in the negative current command. However, the line-currents become square-wave current commands with a $120^{\circ}$ phase-shift. The duty cycle of the line-currents, therefore, is $2 / 3$. In each $180^{\circ}$, the $120^{\circ}$ is turned on and another $60^{\circ}$ is turned off. In addition, the amplitude of the line currents is 1.5 times of the amplitude of the phase-current commands. By using this $\Delta$ - connected winding, one can obtain a larger current and larger torque than the Y-connected winding. As a result, the output torque of the $\Delta$-connected winding is larger than the output torque of the Y-connected winding when they have the same DC input voltage and the same size of the brushless DC motor.

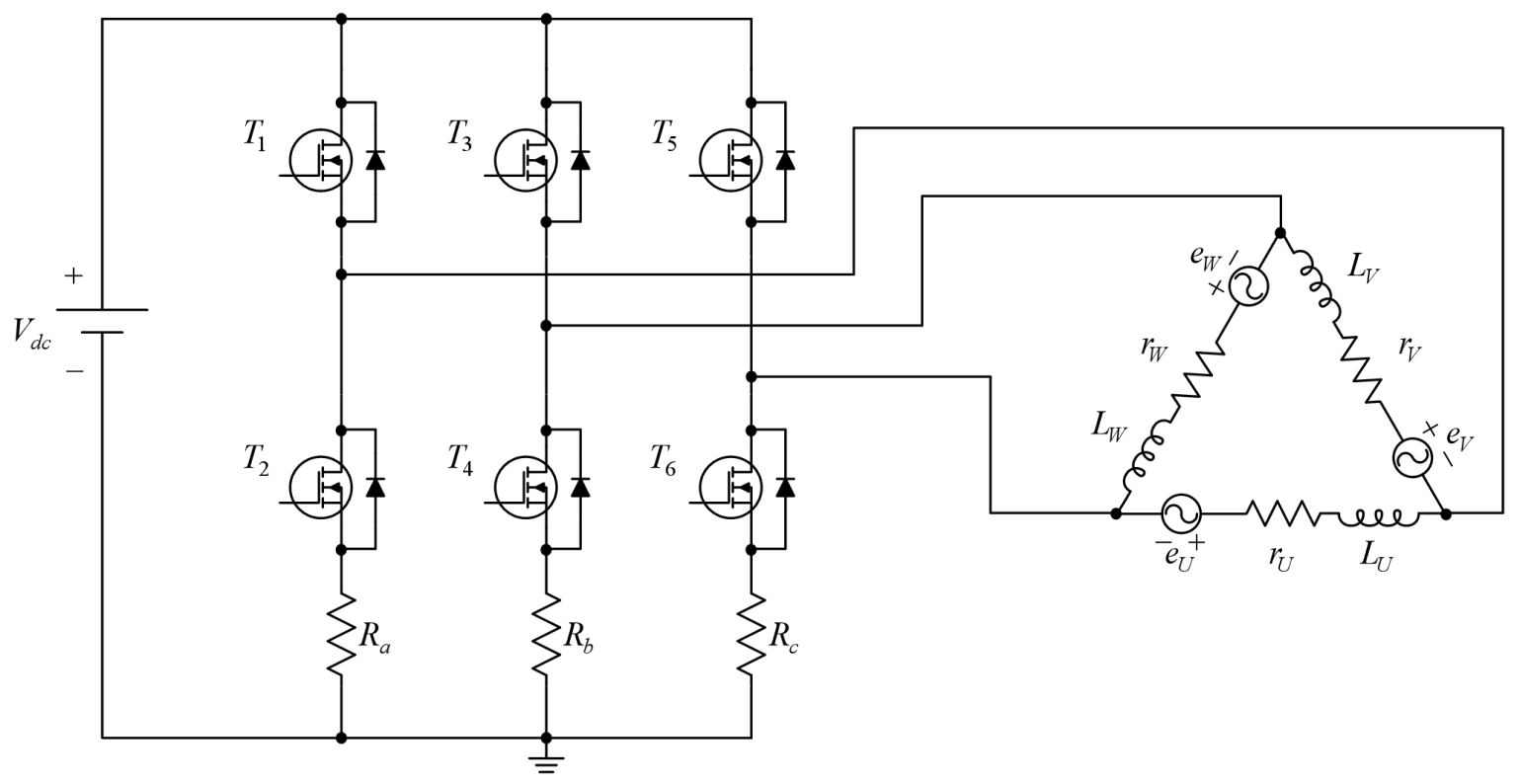

(a) 


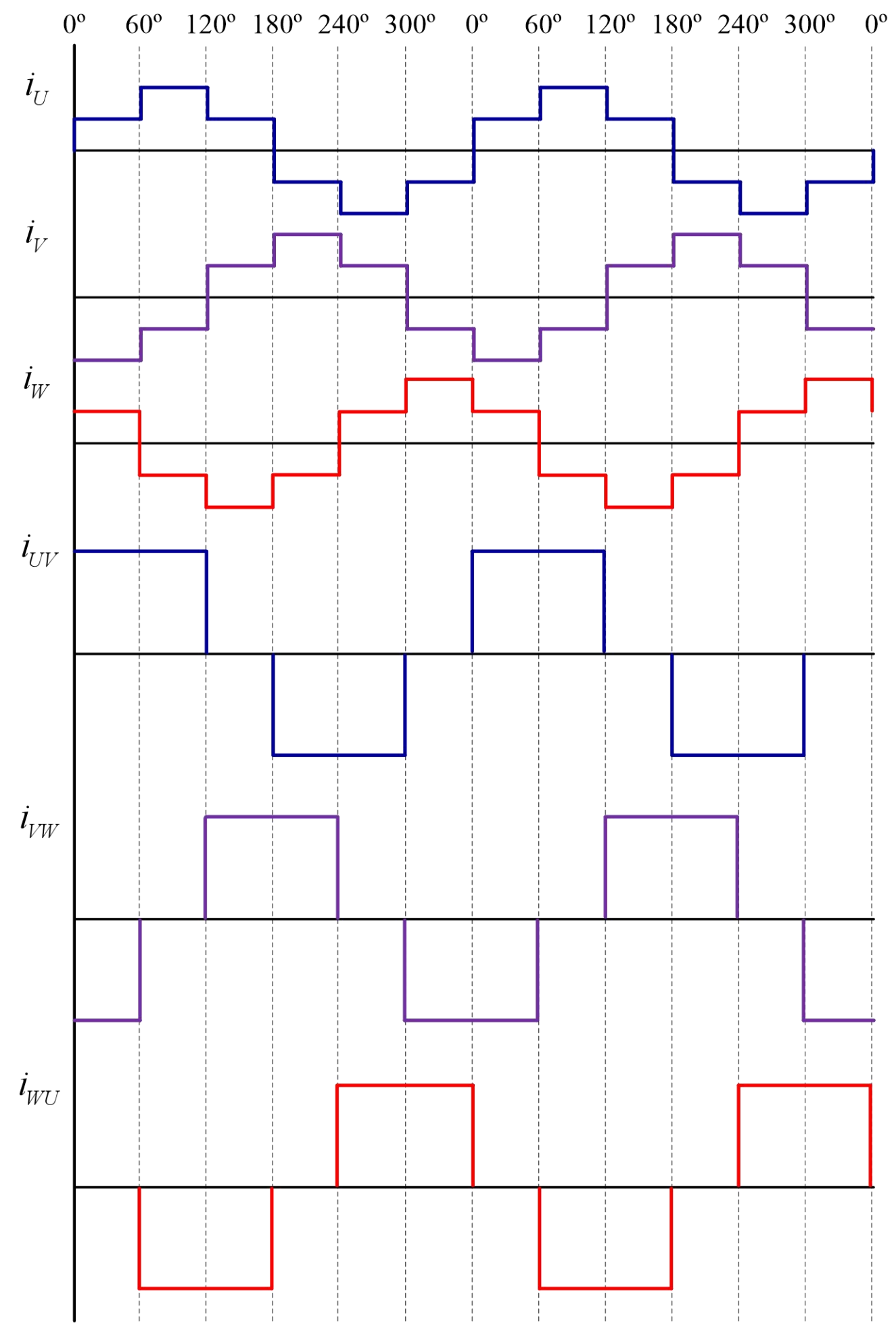

(b)

Figure 4. The $\Delta$ - connected brushless DC motor drive system. (a) MOSFET- inverter-driven main circuit (b) phase-current and line-current commands.

\section{Implementation}

In this paper, the implemented electric hand-tool includes two major parts: hardware circuits and DSP software programs ${ }^{[10-13]}$. Figure 5(a) shows the implemented hardware circuits that consist of a brushless DC motor, a three-phase MOSFET inverter, driving circuits, a power supply, a Li-battery set, a 7-segment display circuit, a DSP, a current feedback circuit, and a protection circuit. The Li-battery supplies the DC voltage to the input side of the three-phase inverter and the 
power supply. The inverter converts the DC voltage into three-phase output voltages to the brushless DC motor. The brushless DC motor also converts the three-phase electric energy into mechanical energy to operate the electric hand-tool. The power supply converts the Li-battery voltage to different voltages to the power supplies, the DSP, and other circuits. The drive circuit provides the functions of isolation and increases its driving capability to turn on or turn off the inverter. The current feedback and protection circuit converts the motor currents into digital values, which can be read by the DSP. The Hall-sensor UVW circuit is used to detect the required commutation phase of the brushless DC motor. The 7-segment display shows the estimated torque of the electric hand tool.

Figure 5(b) shows the photograph of the implemented hand-tool, which includes the hand-tool, the inverter, the 7-segment LED, and the DSP that is used to execute the control and estimating algorithms.

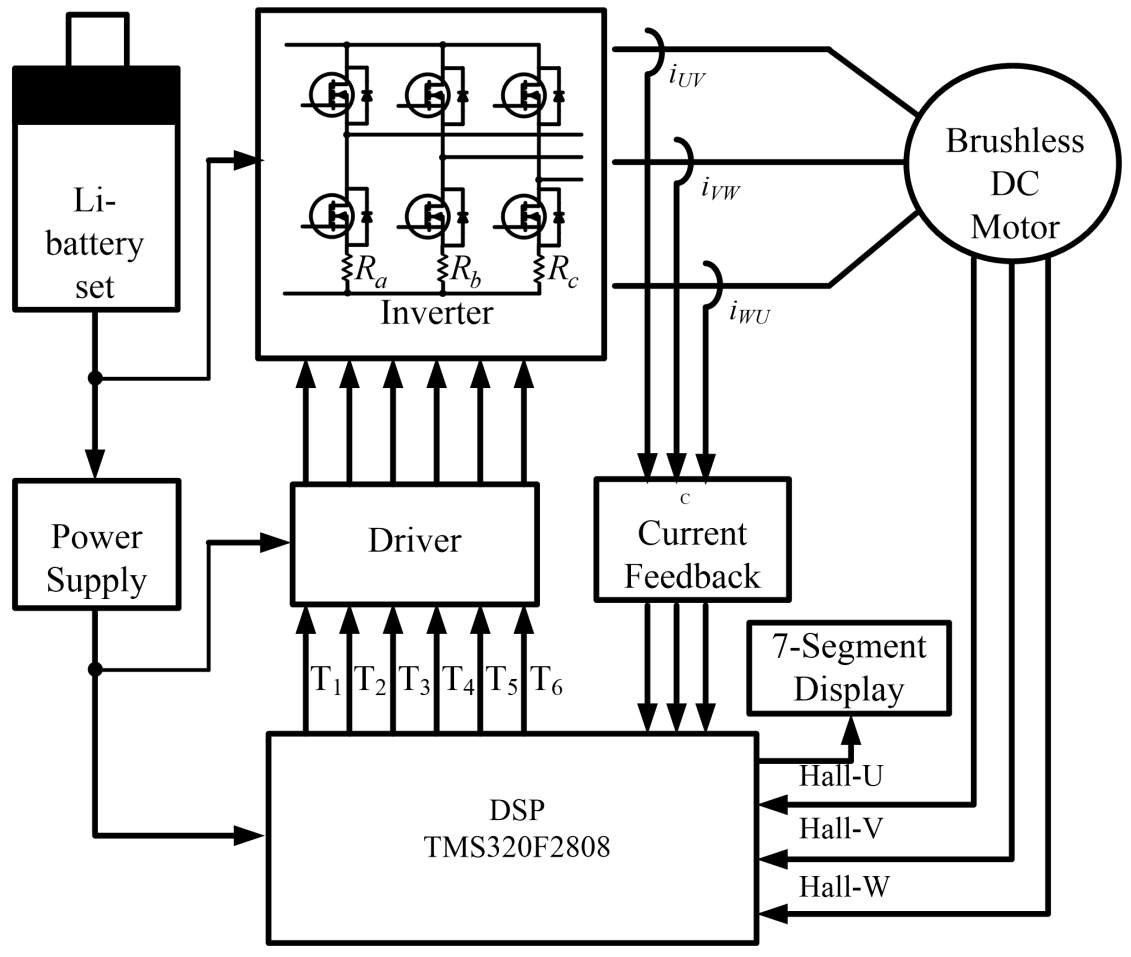

(a)

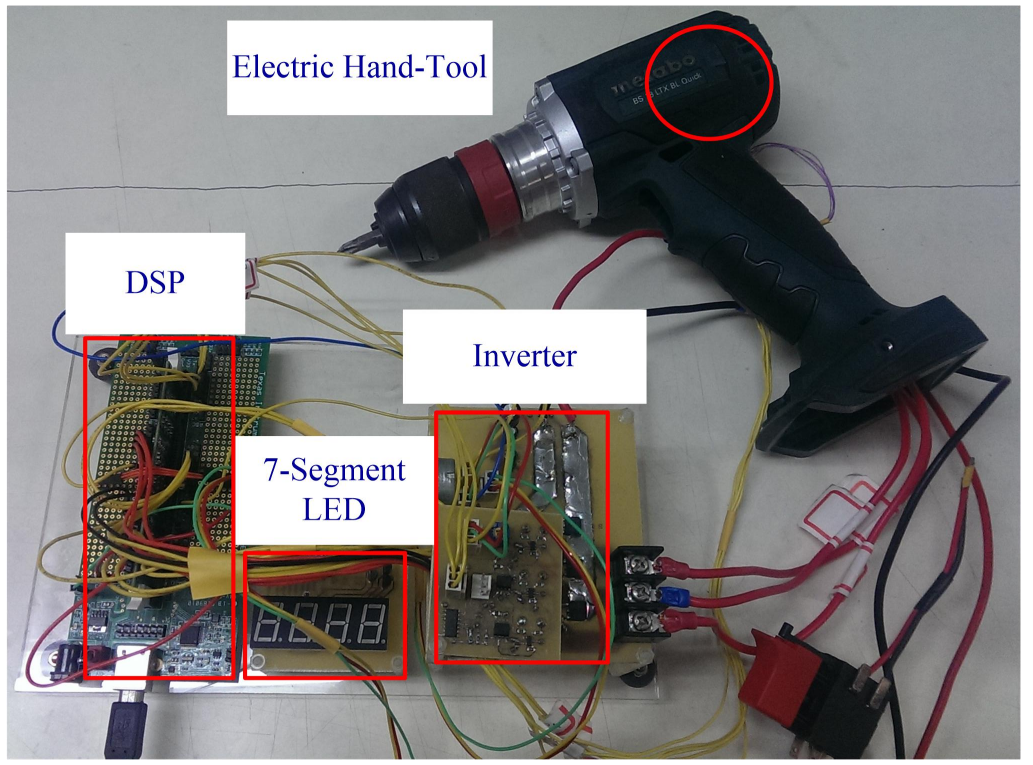

(b)

Figure 5. The implemented electric hand-tool. (a) block diagram (b) photograph. 


\subsection{Hardware circuits}

Figure 6(a) shows the brushless DC motor, which was manufactured by Johnson Electric Company in the USA. The motor is $\Delta$-connected and the parameters of the motor are shown as follows. The motor has 4-poles, and a rated speed of $26000 \mathrm{r} / \mathrm{min}$, and stator inductances are $40 \mu H$, and stator resistances are $0.15 \Omega$. Figure 6(b) shows a photograph of the Li-battery, which is $18 \mathrm{~V}$ and 4Ah, and is made by Metabo Company. Figure 7(a) shows the booth-strap circuit with an IR2181 integrated circuit. The specifications of the IR2181 is shown in Table 1. When the MOSFET $Q_{L}$ turns on, $15 \mathrm{~V}$ flows through the diode $\mathrm{D}$ to charge the capacitor $\mathrm{C}$ until it reaches $15 \mathrm{~V}$. When the MOSFET $Q_{L}$ turns off, the capacitor voltage charges the integrated circuit IR2181 and then the $Q_{H}$ turns on. As a result, the capacitor reduces its voltage due to the release of energy. Finally, the $Q_{H}$ turns off and the MOSFET $Q_{L}$ turns on again Figure 7(b) shows the current sensing circuit. First, the resistance $\mathrm{R}$ is put in series with one phase of the stator winding to detect its current. Next, an amplifier is implemented to enhance the detecting signal by 50 times. After that, a resistance $R_{\text {filter }}$ and a capacitor $C_{\text {filter }}$ is used to remove the high-frequency noise. The operational amplifier, MCP6291, has specifications shown in Table 2. Figure 7(c) shows the over-current protection circuit. When either current of $I_{U}, I_{V}$, and $I_{w}$ exceeds the current limitation, the output of the OPA becomes "0". Then the AND gate becomes "Low". Finally, the DSP disables the trigger signals. Figure 7(d) shows the 7-segment display, and a 4-digit LED is implemented. Two digits are used to show the integral, and the other two digits are used to show the decimal. As a result, the 7-segment display can show the torque range from 00.00 Nt.m to 99.99 Nt.m.

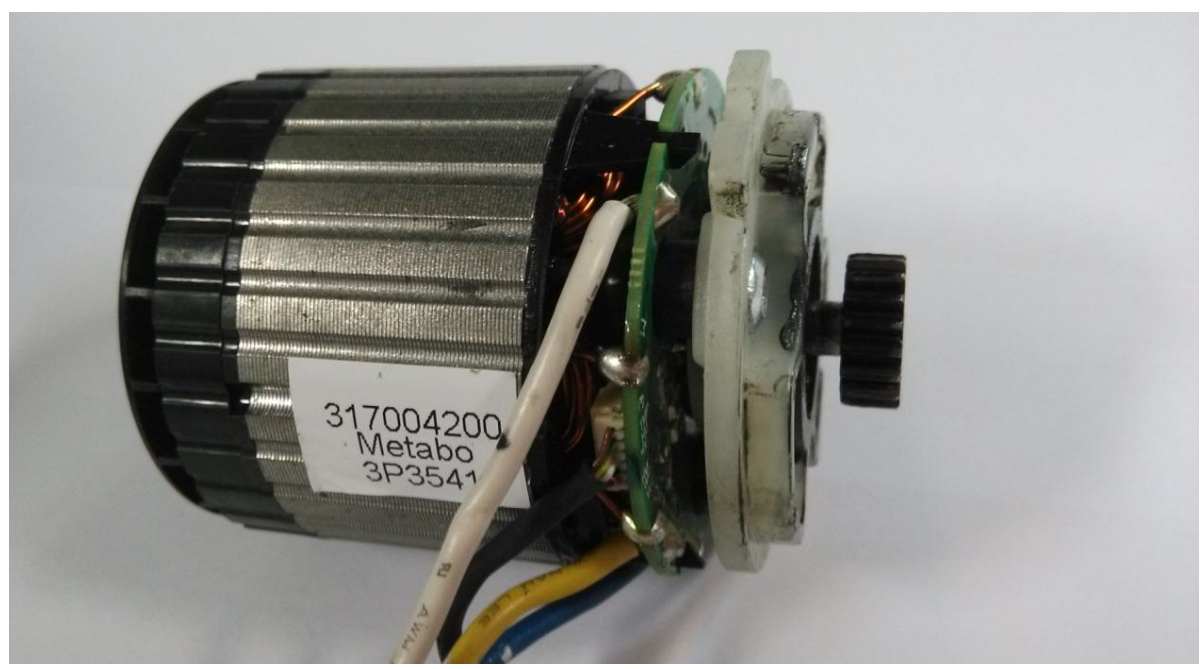

(a)

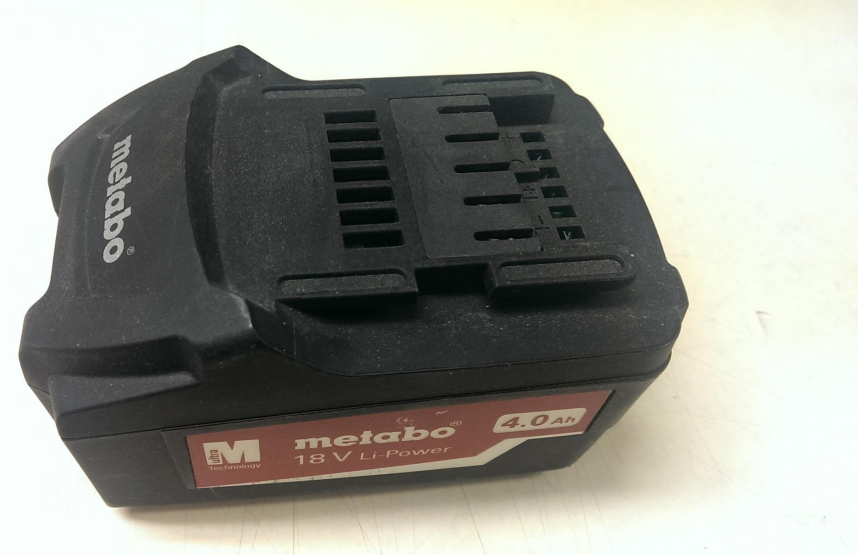

(b)

Figure 6. Brushless DC motor and battery. (a) Brushless DC motor (b) Li-battery. 


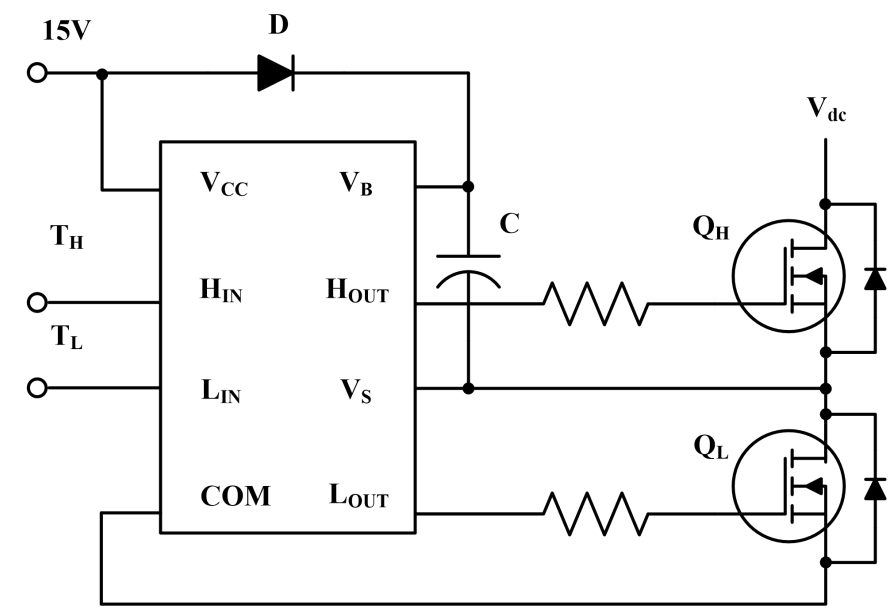

(a)

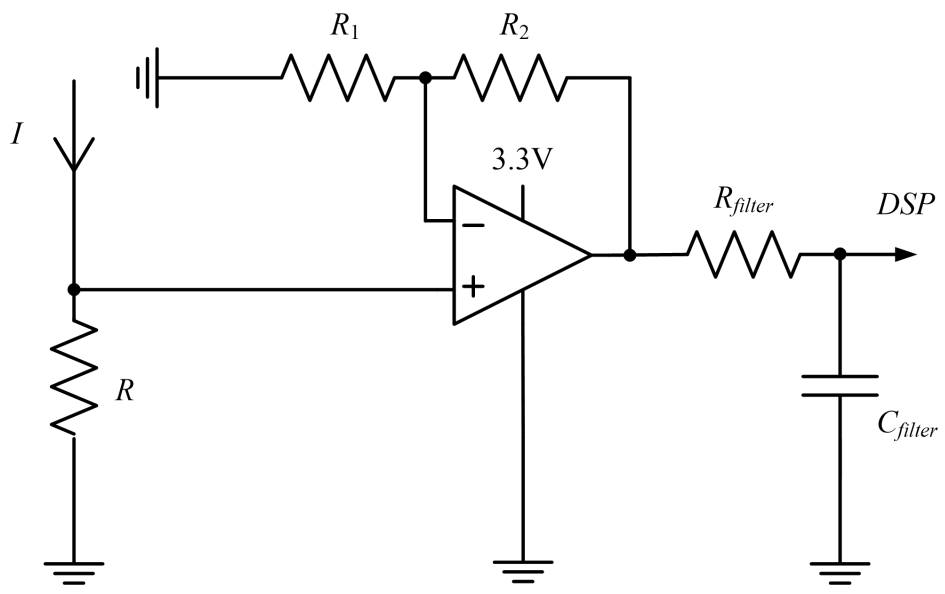

(b) 


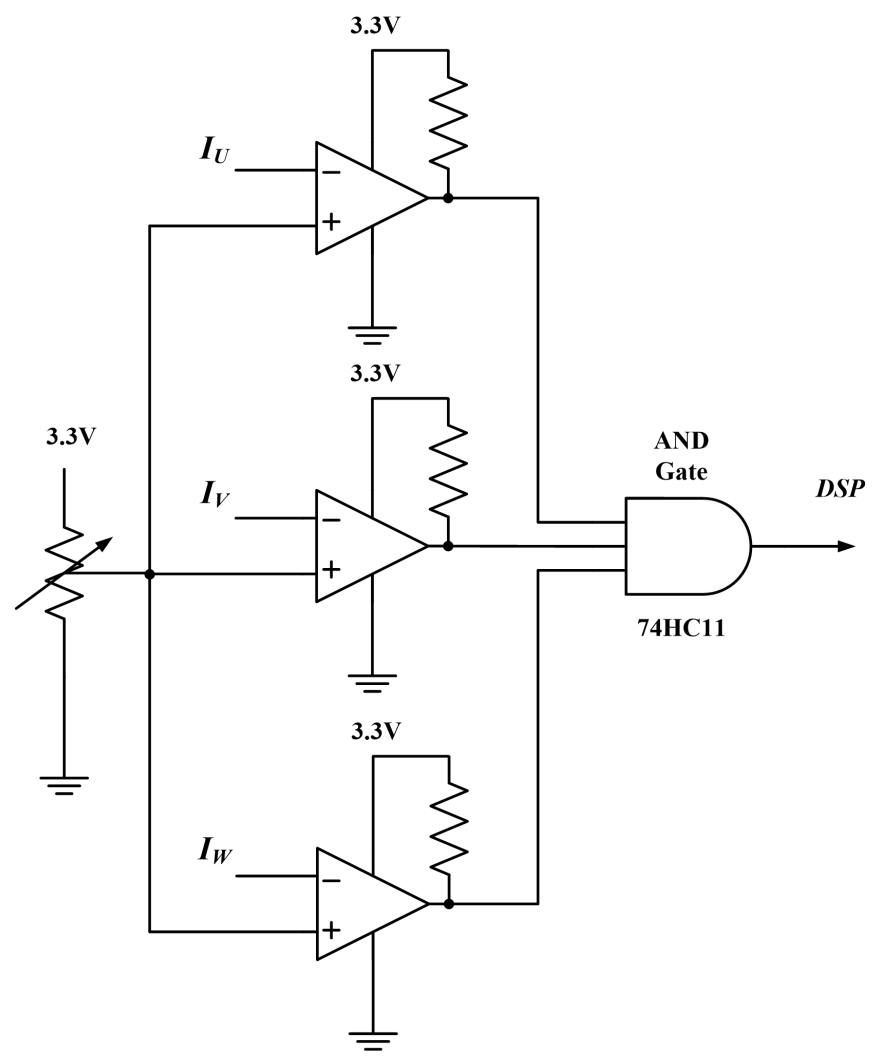

(c)

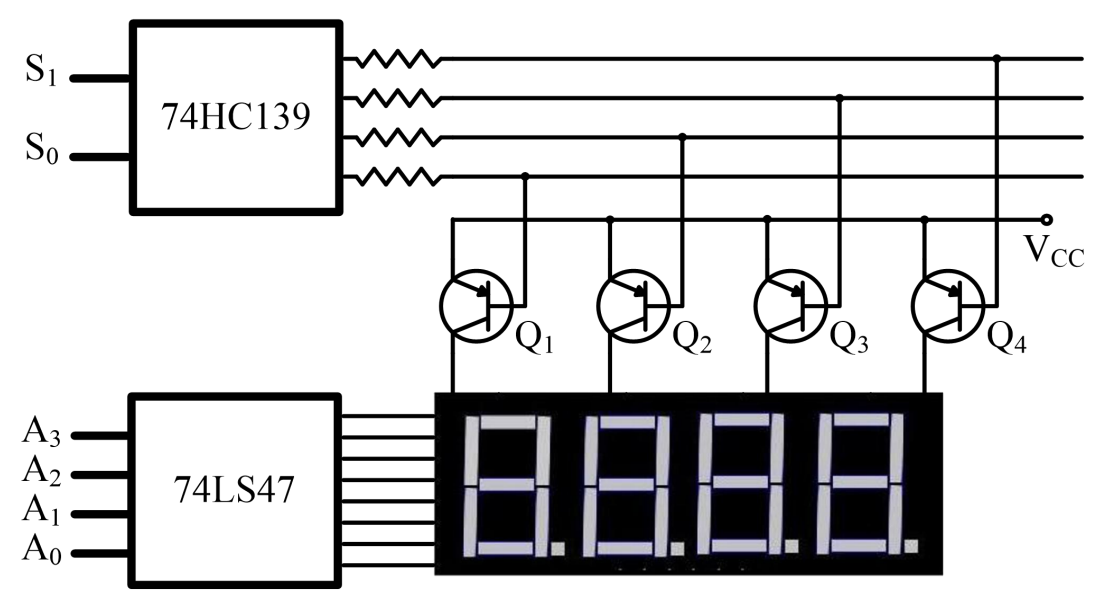

(d)

Figure 7. The hardware circuits. (a)boothstrap circuit (b) current sensing circuit (c) over-current protection circuit (d) display.

\begin{tabular}{|c|c|c|c|c|c|}
\hline $\mathbf{V}_{\mathbf{B}}$ & $\mathbf{V}_{\mathbf{C C}}$ & $\mathbf{t}_{\mathbf{n}}$ & $\mathbf{t}_{\mathbf{r}}$ & $\mathbf{t}_{\text {off }}$ & $\mathbf{t}_{\mathbf{f}}$ \\
\hline $625 \mathrm{~V}$ & $25 \mathrm{~V}$ & $180 \mathrm{~ns}$ & $40 \mathrm{~ns}$ & $220 \mathrm{n} \mathrm{s}$ & $20 \mathrm{~ns}$ \\
\hline
\end{tabular}

Table 1. The specifications of IR 2181

\begin{tabular}{|c|c|c|c|}
\hline Parameters & $\mathbf{V}_{\mathbf{C C}}$ & $\mathbf{I}_{\mathbf{C}}$ & GBWP \\
\hline Values & $2.4 \sim 6.0 \mathrm{~V}$ & $1 \mathrm{~mA}$ & $10 \mathrm{MHz}$ \\
\hline
\end{tabular}

Table 2. The specifications of MCP6291 


\subsection{DSP software programs}

In this paper, DSP programs include a main program, an interrupt service routine, and a sub-program. Figure 8(a) shows the main program, which provides an infinite loop. First, the DSP executes initializations. Next, the DSP enables the interruption. When an interrupt signal is detected, the DSP jumps into the interrupt service routine. Otherwise, the DSP continuously checks if any interrupt requests happen. This continuous checking causes the DSP to go into infinite loops. Figure 8(b) shows the flow chart of the interrupt service routine. The DSP checks if the "start" switch of the hand-tool is pushed. If the "start" switch is pushed, then the DSP checks if the hand-tool is overcurrent. If the hand-tool is overcurrent, the DSP disables the inverter and then returns to the main program. However, if the hand-tool is not overcurrent, the DSP computes the average current, executes the PI current controller, and estimates the output torque. Finally, the DSP checks if the program has ended or not. If it has ended, the DSP goes back to the main program. Otherwise, the DSP drives the motor. Figure 8(c) shows the subprogram for "driving the motor". First, the DSP checks if the duty is greater than $50 \%$. If it is not, then the DSP returns to the interrupt service routine. However, if it is greater, then the DSP checks if the hand-tool is touching an object. If the hand-tool is touching the object, then the DSP stops the triggering of the inverter. If the DSP detects that the duty is less than $50 \%$, the DSP checks if the hand-tool requires constant torque. If this is true, then the DSP provides constant torque. After that, the DSP checks that the counter has counted down to zero. If it is true, then the DSP records the torque and stops the brushless DC motor and returns to the interrupt service routine. The flow charts of the DSP software programs are as follows, which include a main program, an interrupt service routine, and a sub-program. The details are as follows ${ }^{[13-16]}$.

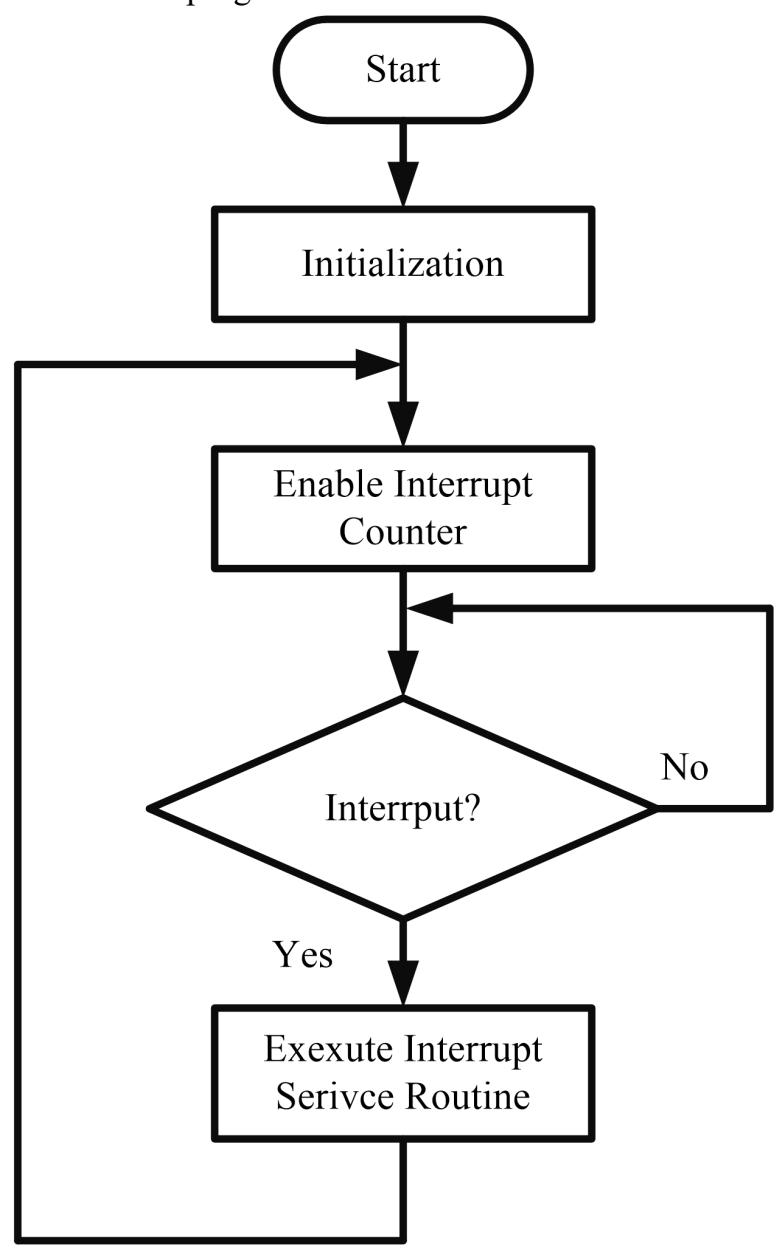

(a) 


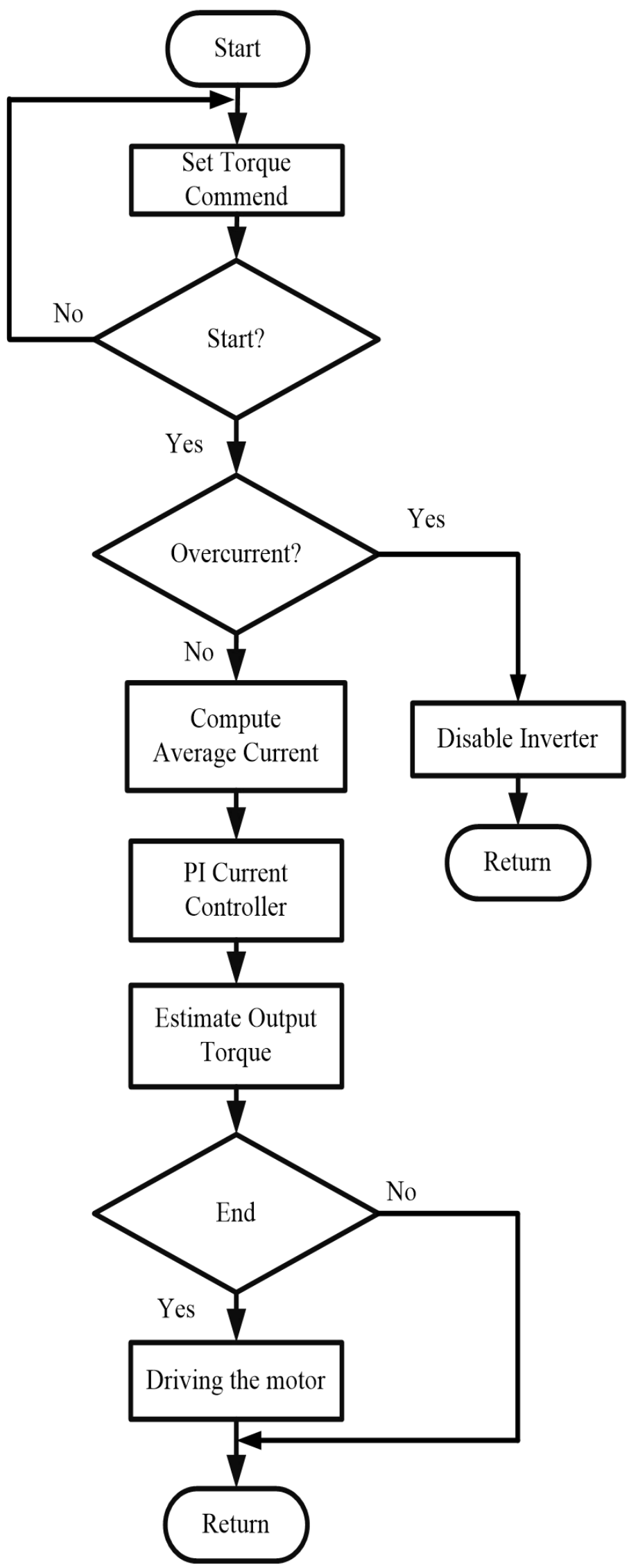

(b) 


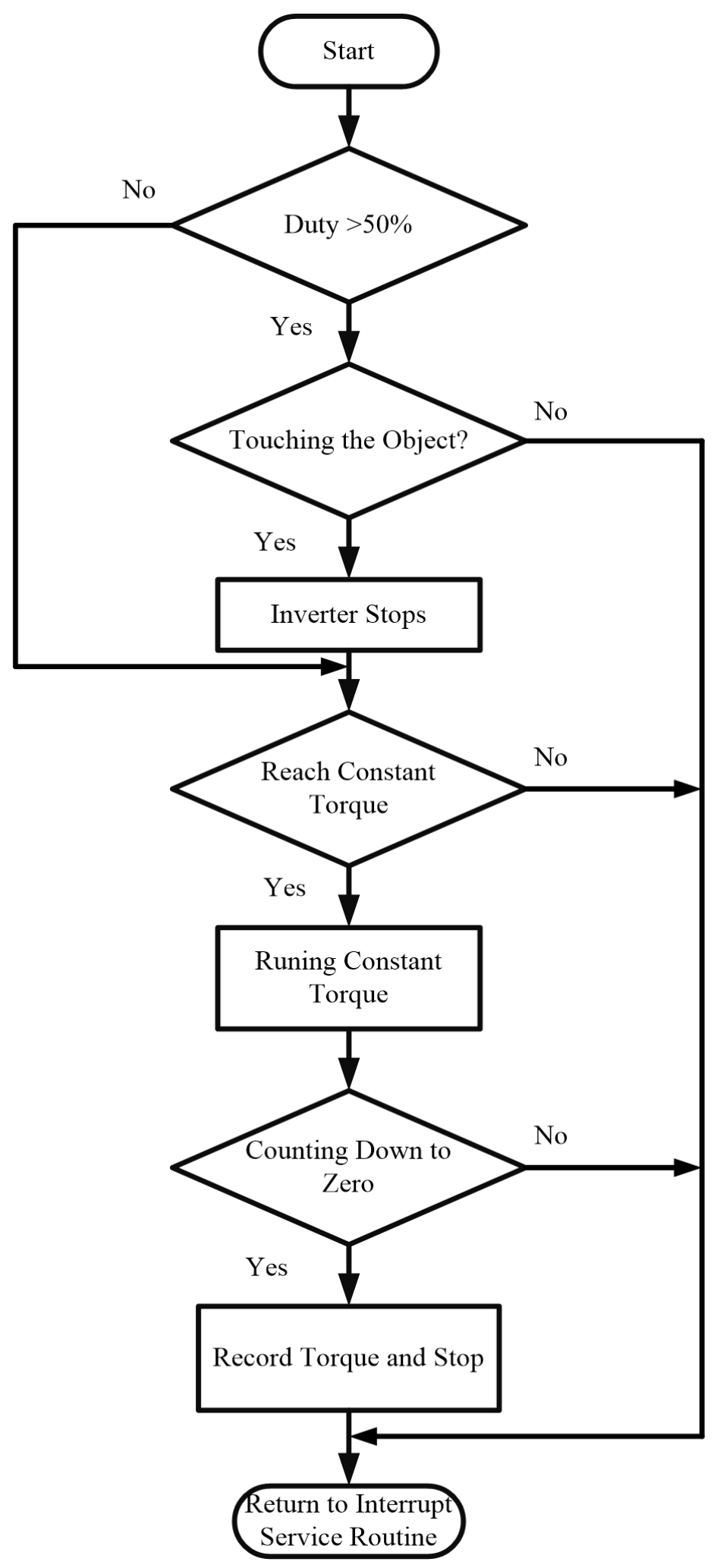

(c)

Figure 8. Flow-charts of the DSP programs.

\section{Experimental results}

To evaluate the implemented brushless DC drive system, a test bench is set up and shown in Figure 9(a)(b). Figure 9(a) is the photograph of the speed and torque display panels and Figure $\mathbf{9}(\mathrm{b})$ is the dynamometer with a torque sensor, which can measure 
the external load. A dynamometer that is coupled with the hand-tool drive system is established in this paper. The coupled system has a torque sensor and the motor speed and torque can be displayed and then compared to its commands. Several experimental results are shown here to validate the theoretical analysis as follows. The current-loop sampling time is $100 \mu s$, and the speed-loop sampling time is $1 \mathrm{~ms}^{[14-16]}$.

Figure 10(a)(b)(c)(d) show the measured waveforms when the electric hand-tool operates at 50 $\mathrm{r} / \mathrm{min}$ and 12.5 A line current. Figure 10(a) shows the out voltage waveform of the Li-battery, which is near $19 \mathrm{~V}$. Figure 10(b) is the battery output current, which is near 1.25A. The current has obvious ripples due to the PWM switching, and the output current has a ripple near $\pm 0.2 \mathrm{~A}$. Figure 10 (c) shows the line-current of the brushless DC motor, which is near 12.5 A. Figure 10(d) shows the line-line voltage, which is near $20 \mathrm{~V}$. The switching frequency of the line voltage is near 20 $\mathrm{kHz}$. Figure 11 shows the estimated torque constant and the measured torque constant. Both constants are near 0.397 N.m/A and are very close. A detailed comparison, shown in Figure 8, is listed in Table 1. Figure 12 shows the relationship between the measured torque and its estimated torque. Both the measured results and the estimated results are linear. In addition, they are very close even though they have different values. Figure 13(a)(b) show the measured current responses at 5 N.m and 9 N.m. Both of responses require a 0.5 second rise time. Figure 14(a)(b) shows the sampling time at a line current of $6.5 \mathrm{~A}$. It can be observed that the sampling point is near the center of the switching interval. As a result, the sampling current is very close to its average current. Figure 15(a)(b) show the measured speed responses of the electric hand-tool and Figure 15(a) shows the no load speed response. The brushless DC motor can reach $260000 \mathrm{r} / \mathrm{min}$ with a rise time of 0.5 seconds. Figure 15(b) shows the speed response when the hand-tool is driving a screw. The motor speed drops to zero quickly as the hand-tool finishes its job at 0.8 seconds. Table 3 shows the comparison between the torque commands and the measured torques. The maximum error of the measurements is $4.5 \%$.

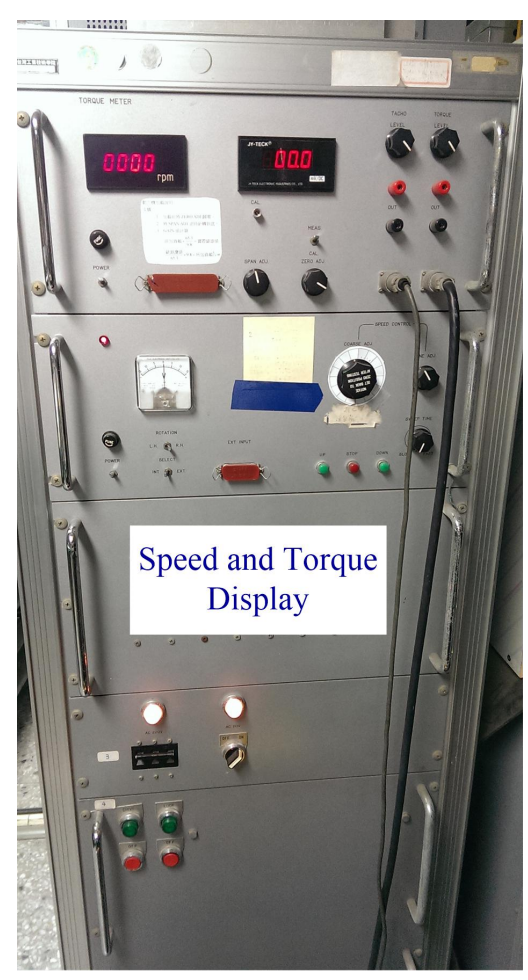

(a)

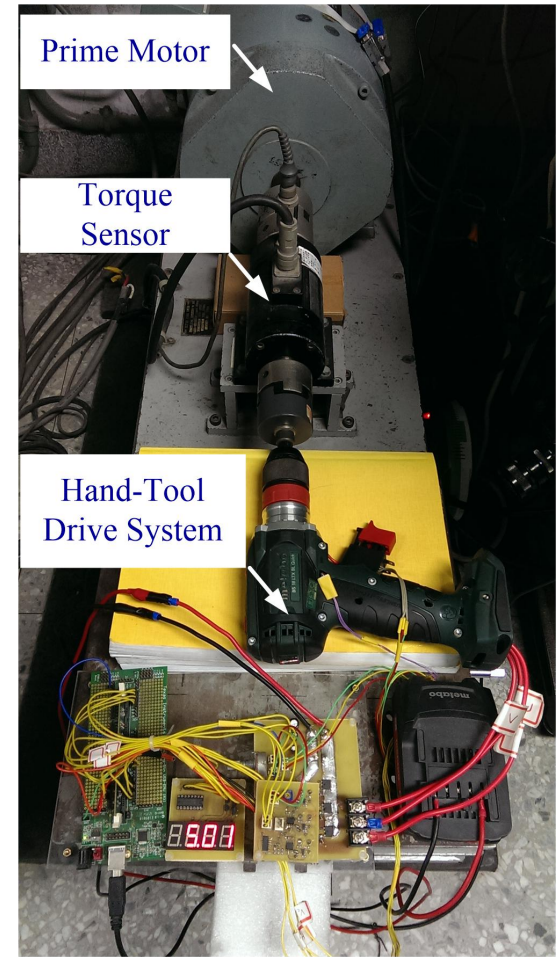

(b)

Figure 9. The photograph of the test bench. (a) speed and torque display (b) dynamometer. 
Voltage(V)

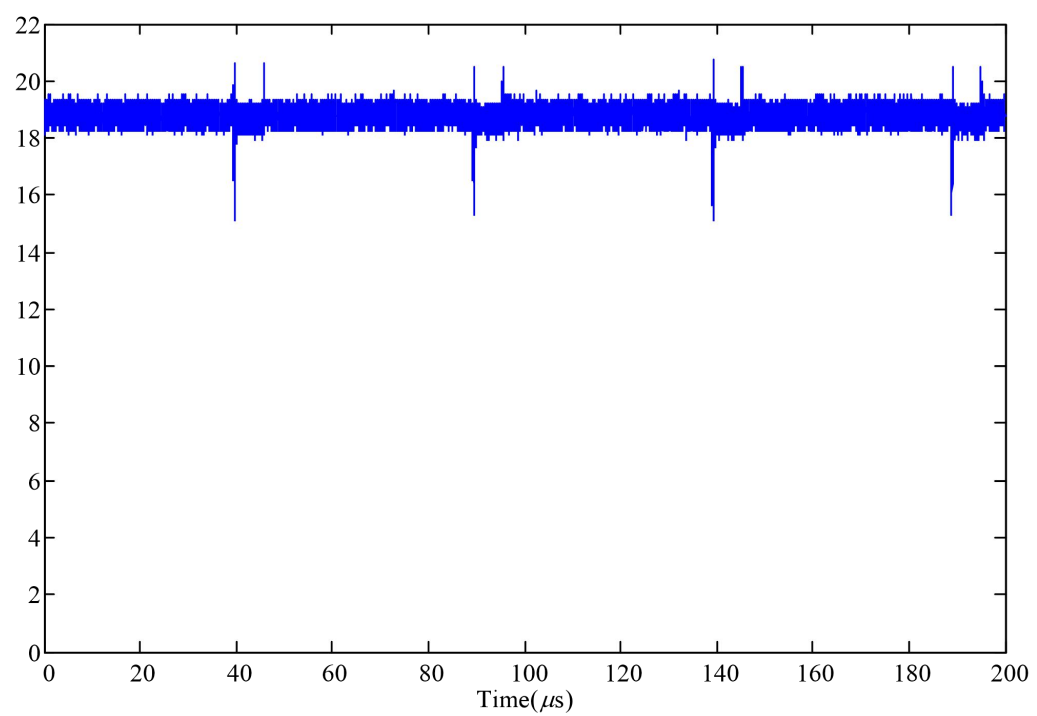

(a)

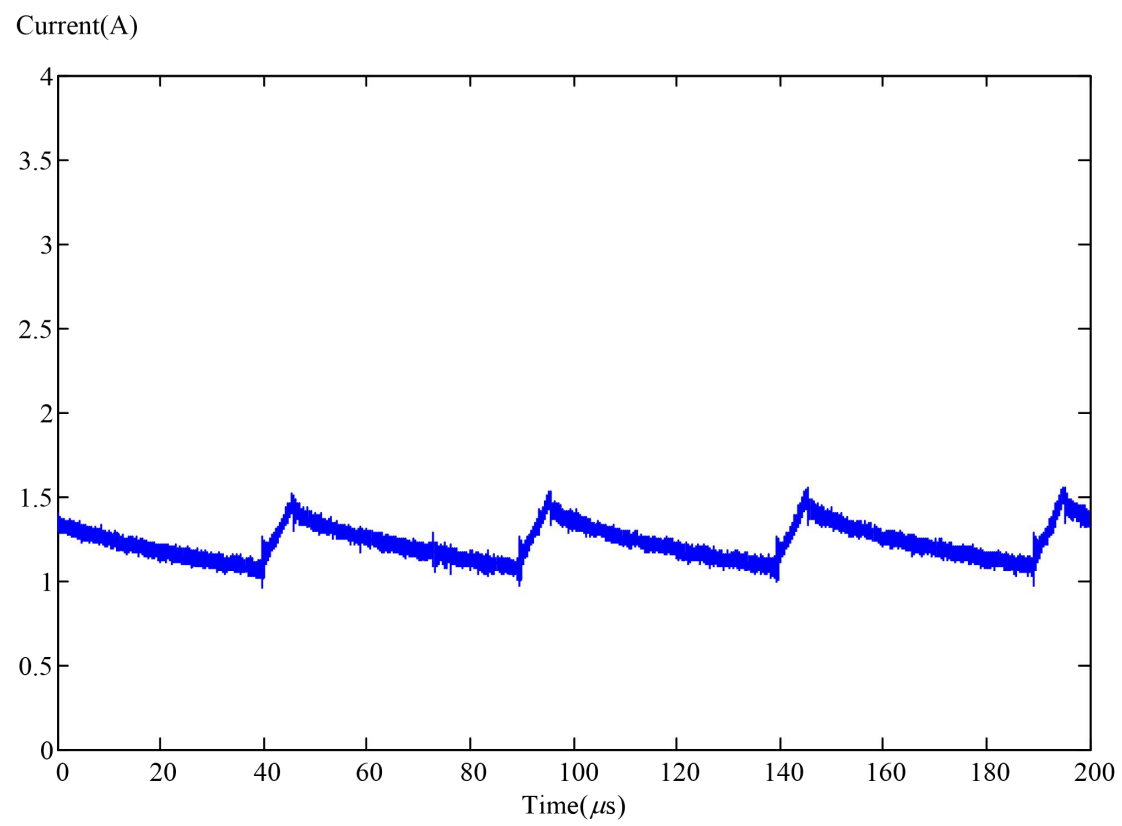

(b) 


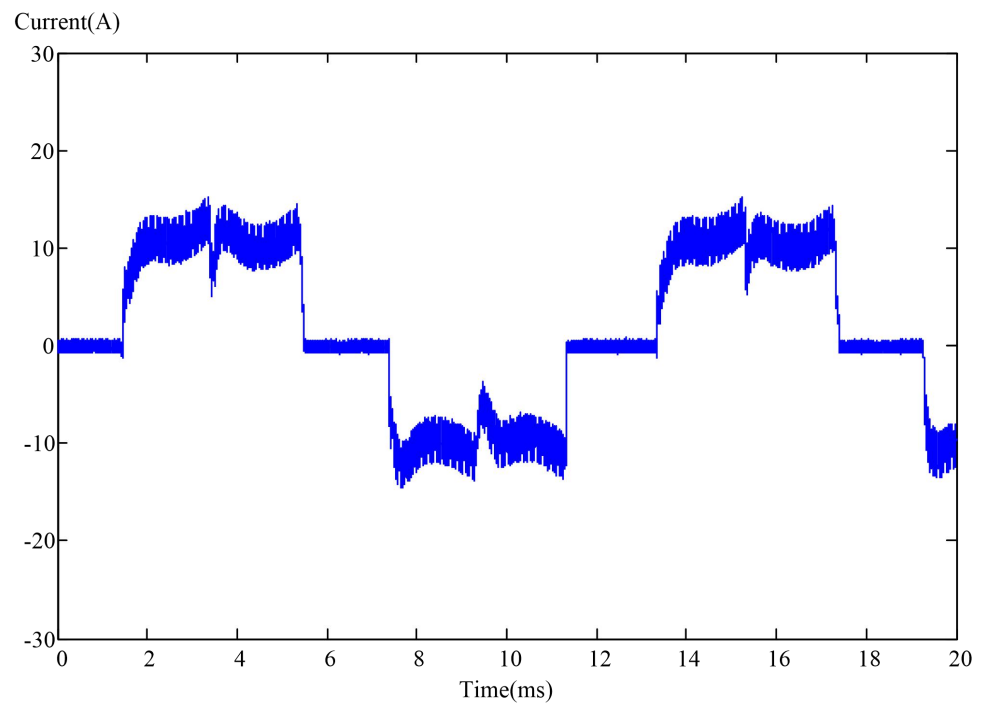

(c)

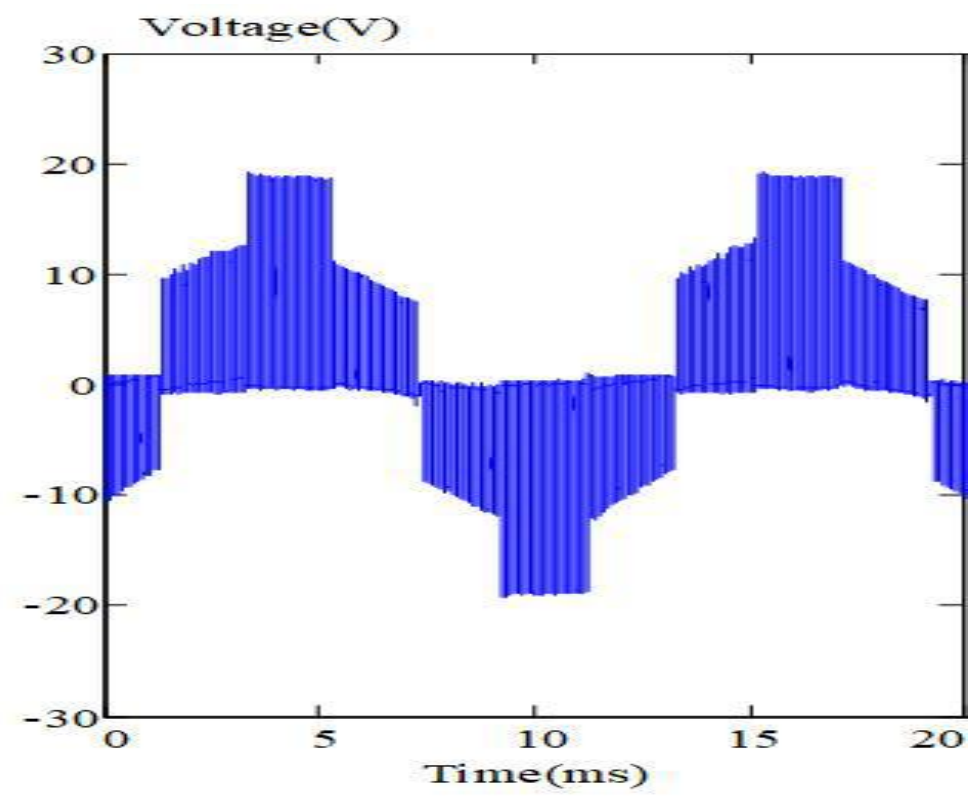

(d)

Figure 10. Measured waveforms when the electric hand-tool is at $50 \mathrm{r} / \mathrm{min}$ and $12.5 \mathrm{~A}$. (a) battery voltage (b) battery voltage (c) line-current (d) line-line voltage. 


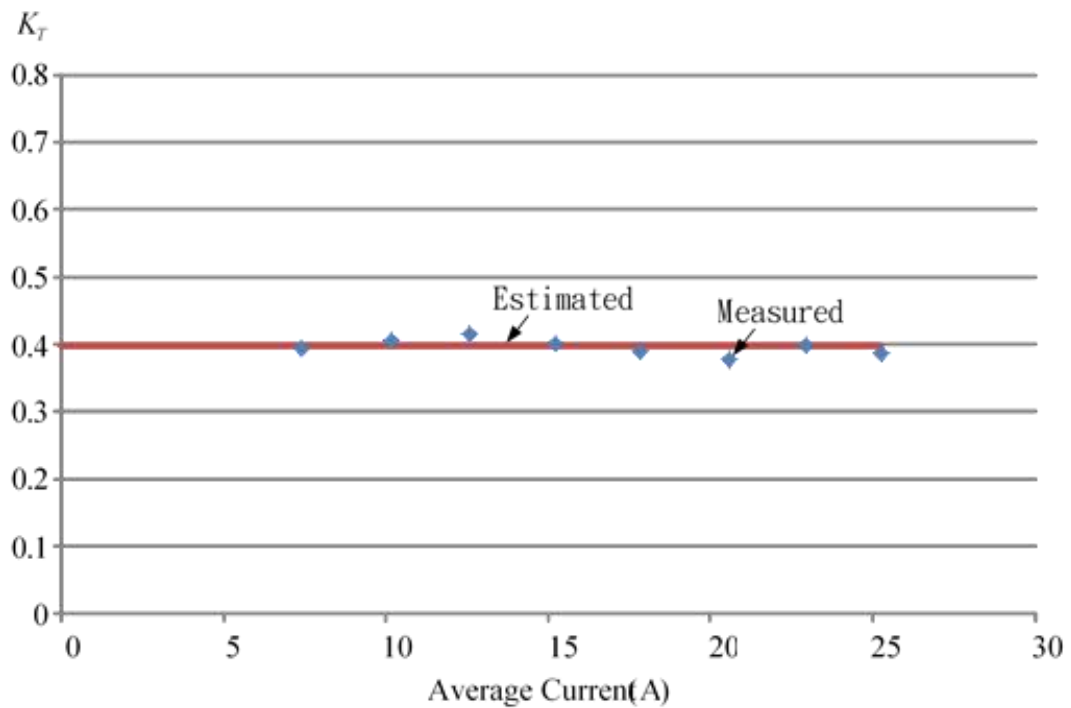

Figure 11. The estimated and measured torque constants.

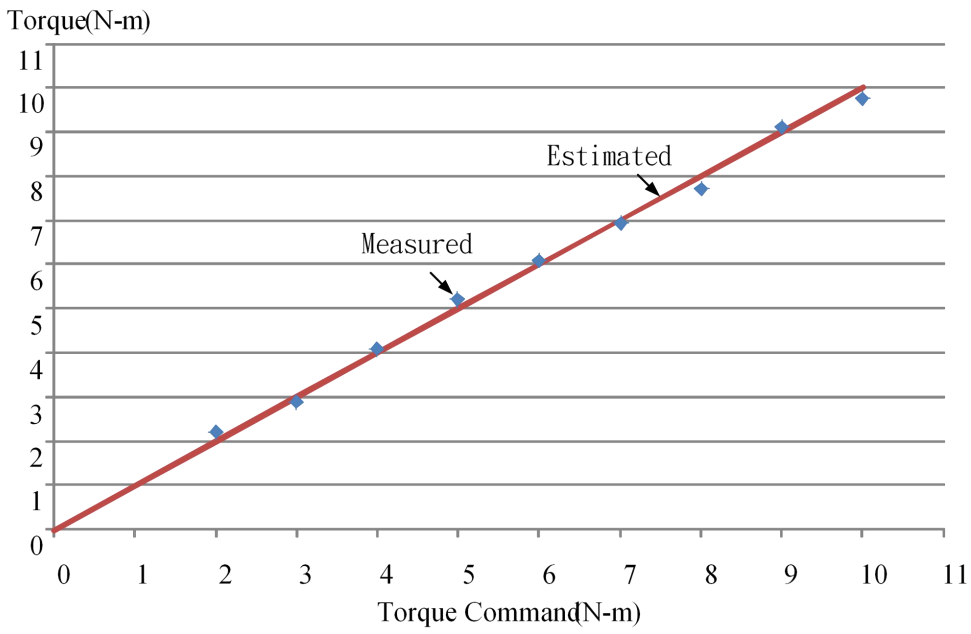

Figure 12. The relationship between measured torque and estimated torque. 
Current Command(A)

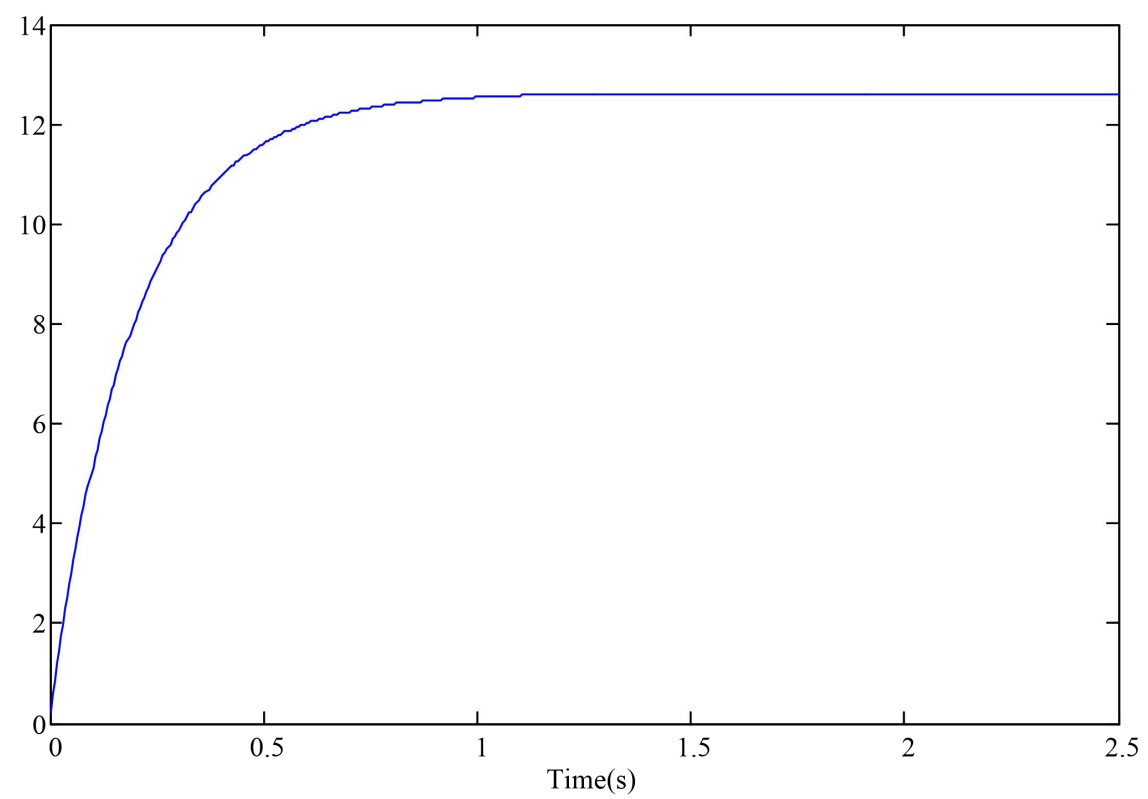

(a)

Current Command(A)

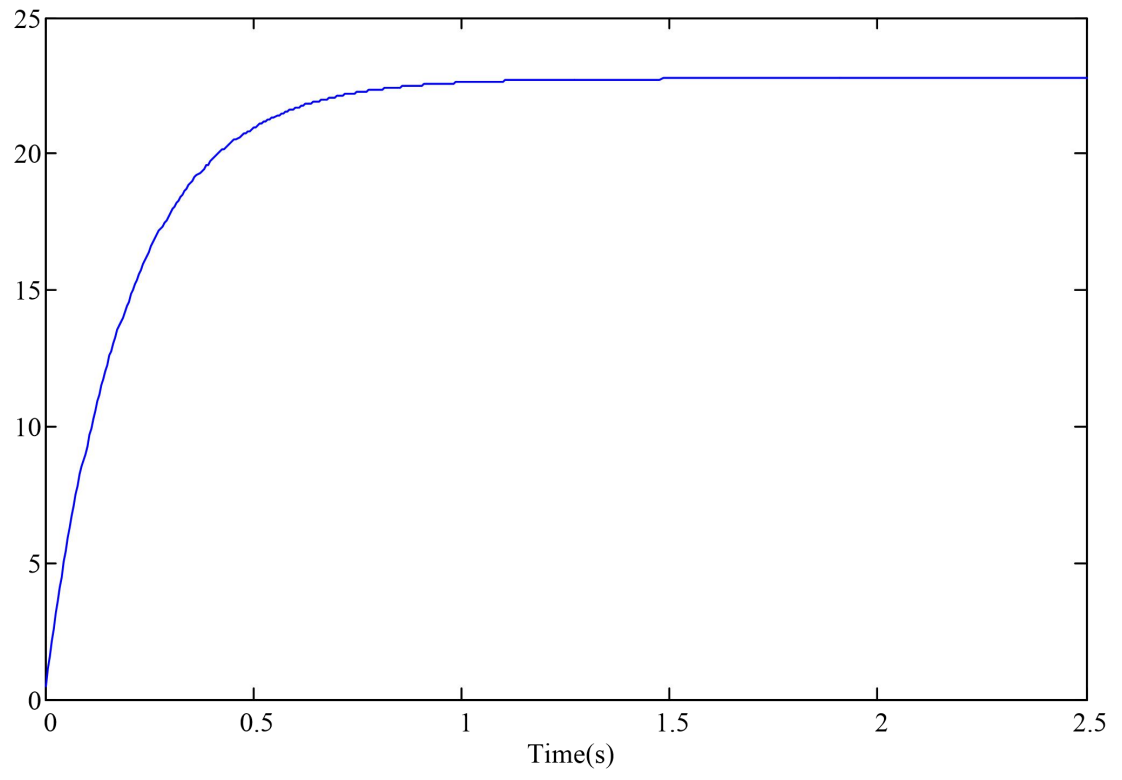

(b)

Figure 13. The measured current responses at different load commands. 


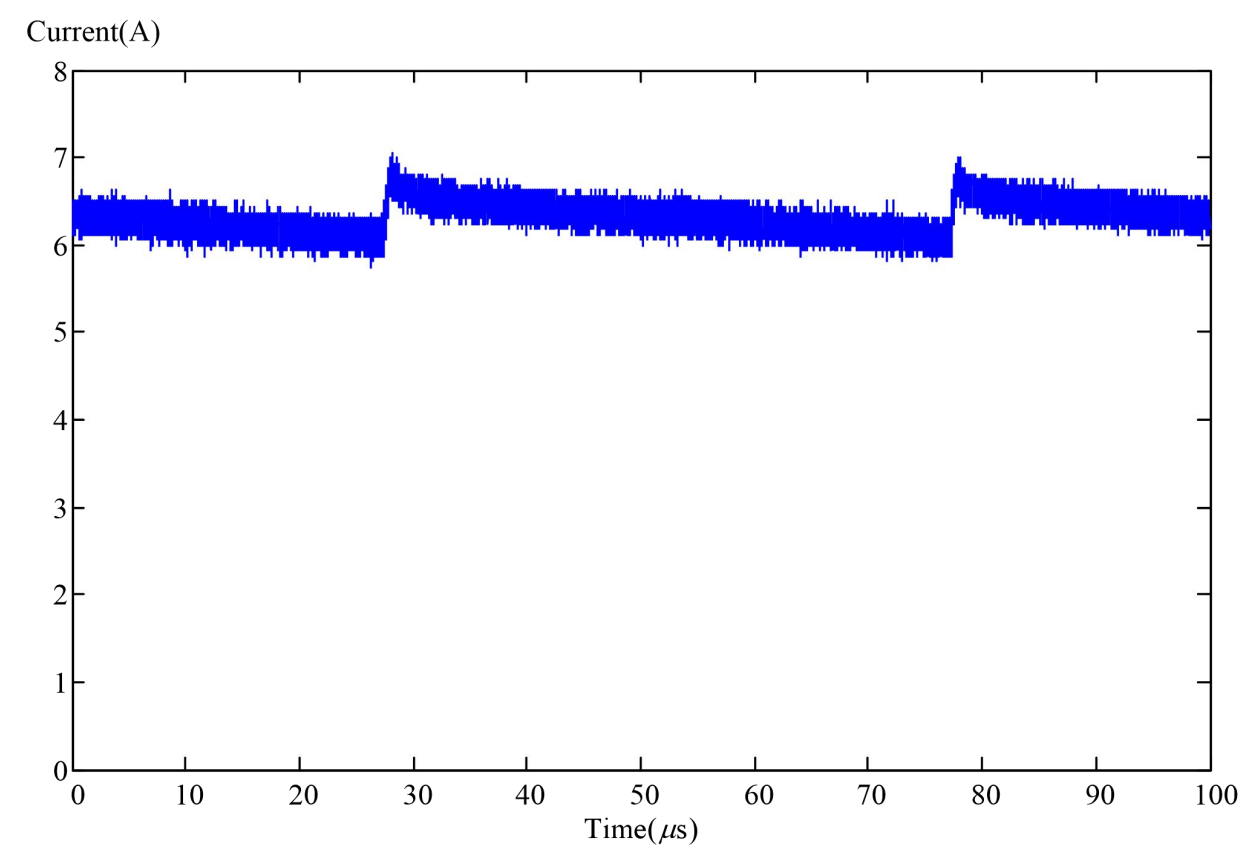

(a)

Voltage $(\mathrm{V})$

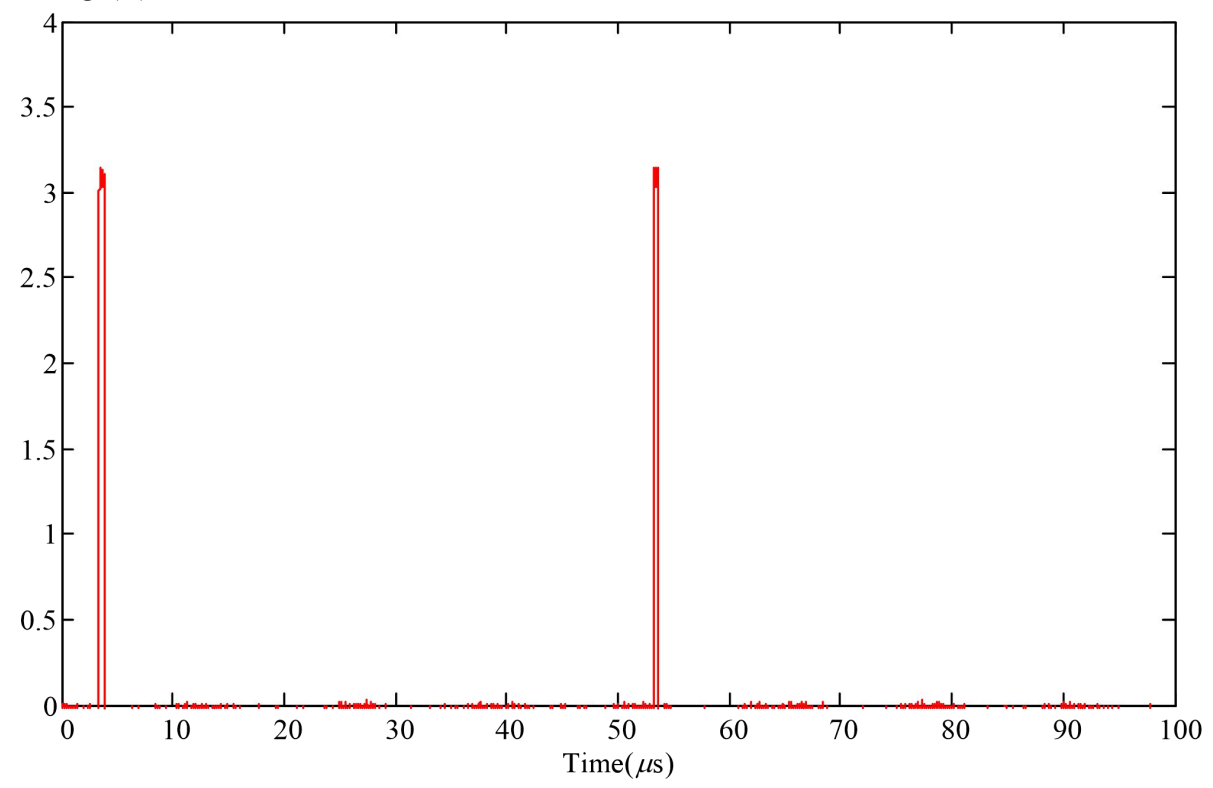

(b)

Figure 14. Measurement of the sampling point. (a) measured line-current (b) sampling point. 


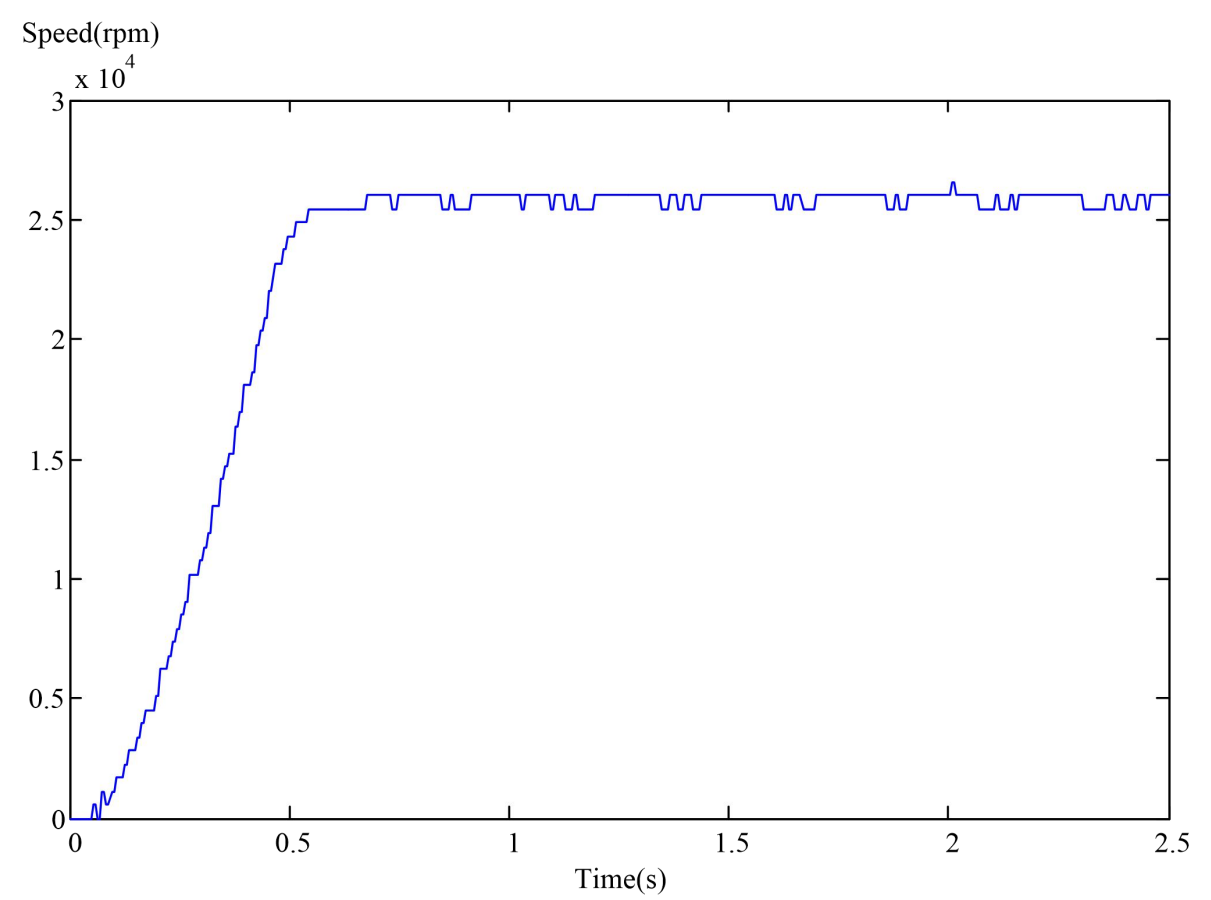

(a)

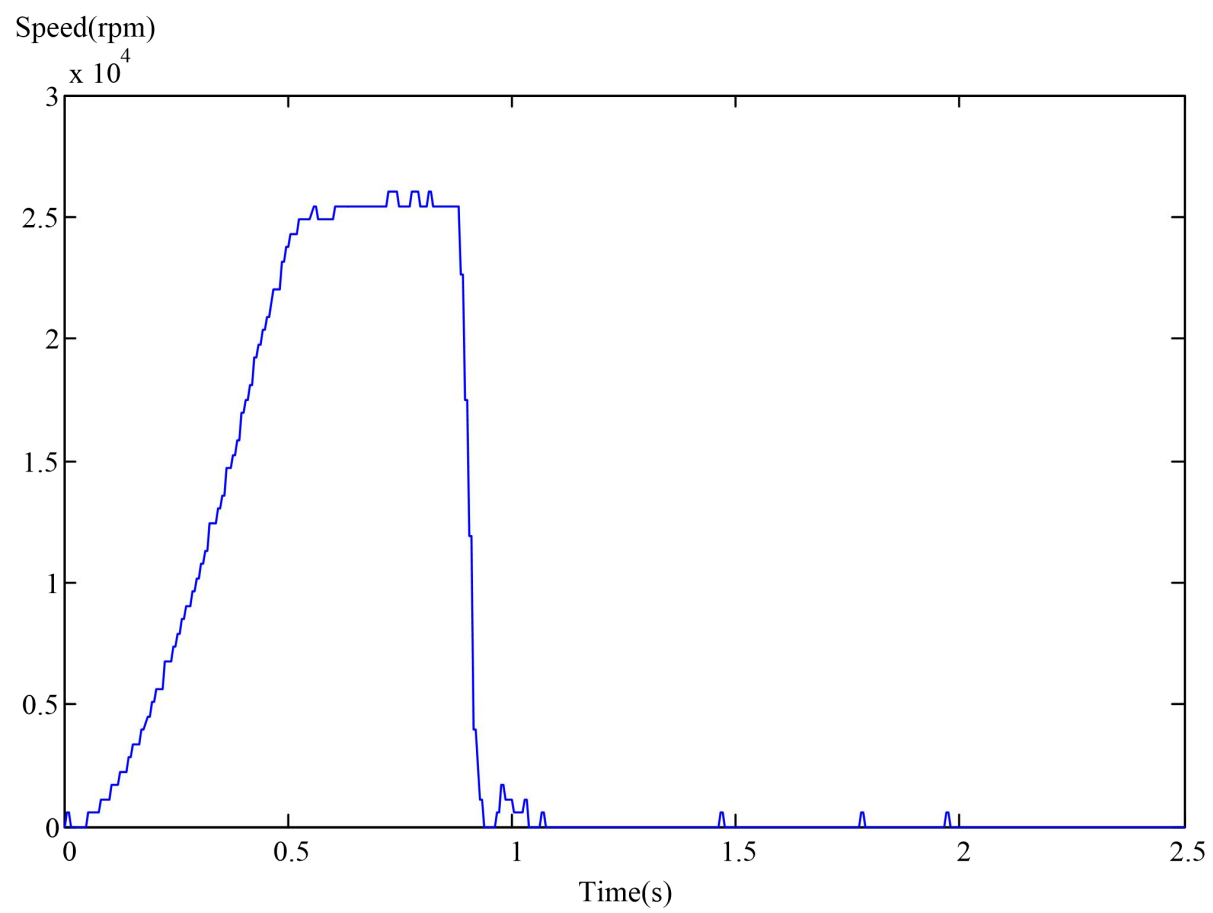

(b)

Figure 15. Measured speed responses. (a) no load (b) driving a screw. 


\begin{tabular}{|c|c|c|c|}
\hline $\begin{array}{l}\text { Torque Command } \\
\text { (N-m) }\end{array}$ & $\begin{array}{l}\text { Measured Torque } \\
\text { (N-m) }\end{array}$ & $\begin{array}{l}\text { Errors } \\
(\mathrm{N}-\mathrm{m})\end{array}$ & $\begin{array}{c}\text { Errors } \\
(\%)\end{array}$ \\
\hline 2 & 2.21 & -0.1 & $-4.5 \%$ \\
\hline 3 & 2.90 & 0.10 & $3.3 \%$ \\
\hline 4 & 4.11 & -0.11 & $-2.8 \%$ \\
\hline 5 & 5.19 & -0.19 & $-3.8 \%$ \\
\hline 6 & 6.09 & -0.09 & $-1.5 \%$ \\
\hline 7 & 6.92 & 0.08 & $1.1 \%$ \\
\hline 8 & 7.71 & 0.29 & $3.6 \%$ \\
\hline 9 & 9.09 & -0.09 & $-1.0 \%$ \\
\hline 10 & 9.75 & 0.25 & $2.5 \%$ \\
\hline
\end{tabular}

Table 3. Comparison between torque commands and measured torques

\section{Conclusions}

In this paper, an electric hand-tool that is driven by a Li-battery set and does not require any torque transducers or stator current sensors has been implemented. Experimental results show the estimated error is smaller than $4.5 \%$ under an external load from 2 N.m to 10 N.m. As a result, the torque sensor is removed.

The detailed analysis and design are included. Several experimental results can validate the theoretical analysis and show the correctness and feasibility of the proposed method. The implemented electric tool can set adjustable torque commands and varied driving time for different purposes. The implemented electric hand-tool can be used in manufacturing as well as in daily life due to its low cost and functionality.

\section{References}

1. Huang SJ, Huang KC, Huang TC, et al. Design of hybrid power supply system with energy regulation capability for hand-held tools. IEEE Trans. Ind. Electron. 2017; 64(2): 1148-1156.

2. Hesmondhalgh DE, Wain EA. Low-speed motorized dental handpiece. IEE Electric Power Appl. 1978; 1(3): 65-71. doi: 10.1049/ij-epa.1978.0012.

3. Hesmondhalgh DE, Tipping D, Amrani M. Design and construction of a high-speed high-performance direct-drive handpiece. IEE Proceedings1987;
134(6): 286-296. doi: 10.1049/ip-b:19870046.

4. Mecrow BC, Jack AG, Atkinson DJ, et al. High torque machines for power hand tool applications. IEEE PEMD 2002; 644-649. doi: 10.1049/cp:20020192.

5. Koinuma K, Aiso K, Akatsu K. A novel self cooling SRM for electric hand-tools. IEEE ECCE 2018; 6116-6120. doi: 10.1109/ECCE.2018.8557901.

6. Sathyan A, Milivojevic N, Lee YJ, et al. An FPGA-based novel digital PWM control scheme for BLDC motor drives. IEEE Trans. Ind. Electron. 2009; 56(8): 3040-3049. doi: 10.1109/tie.2009.2022067.

7. Shanmugasundram R, Zakariah KM, Yadaiah N. Implementation and performance analysis of digital controllers for brushless DC motor drives. IEEE/ASME Trans. on Mechatron. 2014; 19(1): 231-224. doi: 10.1109/TMECH.2012.2226469.

8. Han Q, Samoylenko N, Jatskevich J. Comparison of brushless DC motor drives with 180/120-degree inverter systems. IEEE CCECE 2007; 111-114. doi: 10.1109/CCECE.2007.35.

9. Krishnan R. Electric motor drives: Modeling, analysis, and control. London, UK: Prentice Hall; 2001

10. Miller TJE. Brushless permanent-magnet and reluctance motor drives. Oxford, UK: Clarendon Press; 1989. doi: 10.1049/pe:19900006.

11. Kenjo T, Nagamori S. Permanent-magnet and brushless DC motors. Oxford, UK: Clarendon Press; 1985.

12. Krishnan R. Permanent magnet synchronous and brushless DC motor drives. NW, USA: CRC Press; 2010.

13. Bose BK. Modern power electronics and AC 
drives. NJ, USA: Prentice Hall; 2001.

14. Texas Instruments. TMS320x280xDigital Signal Processors; 2002.

15. Texas Instruments. TMS320x280X DSP Analog to
Digital Converter; 2004.

16. Texas Instruments. TMS320x280x Enhanced Controller Area Network; 2002. 